\title{
Evaluation of Anti-angiogenic Activity of Centella asiatica Water Extract on Chick Embryo Chorioallantoic Membrane Induced by bFGF
}

\author{
Iwan Sahrial Hamid* and Ngakan Made Rai Widjaja \\ Departement of Basic Veterinary, Faculty of Veterinary, Universitas Airlangga
}

\begin{abstract}
Angiogenesis is a physiological process that involves the formation of new blood vessels. In the cancer growth process, angiogenesis acts by supplying nutrition and oxygen for the cancer cells, carries metabolic waste and biological end product of cancer cells. Therefore the spread of cancer cells to the surrounding cells and tissues is accelerated. The occurrence of angiogenesis shows a change in cancer cell status, from dormant to malignant. Cancer cells induce the formation of angiogenesis through the secretion of various growth factors such as Vascular Endothelial Growth Factor (VEGF) and basic Fibroblast Growth Factor (bFGF).Currently many people turn into treatment using natural materials. One of the natural materials used for cancer therapy is pegagan (Centella asiatica). In this research 25 embryonated chicken eggs (ECE) were divided into five treatment groups. Treatment group I as the control received $60 \mathrm{ng}$ bFGF, treatment group II received neither bFGF nor pegagan leaves (Centella asiatica) water extract, and treatment groups III-V received $60 \mathrm{ng}$ bFGF and C. asiatica leaves water extract of 75, 90 and II $10 \mu \mathrm{g}$. Nine days old ESE were inoculated with bFGF and extract at the same time and then were incubated at $38^{\circ} \mathrm{C}$ for three days to allow the formation of blood vessels in embryonated chicken egg chorioallantoic membrane. Observations were performed microscopically and macroscopically by counting the new blood vessels formed around paper disc. Analysis on VEGF expression were conducted to define the role of angiogenesis growth factor. Research results showed a significant difference of treatment with Centella asiatica water extract on the number of new blood vessels formed. Centella asiatica water extract at the dose of $110 \mu \mathrm{g}$ was the highest in inhibiting the formation of new blood vessels. Centella asiatica water extract also inhibited the expression of VEGF.
\end{abstract}

Keywords : Centella asiatica, antiangiogenic, Corio Allantois Membran, VEGF

\section{INTRODUCTION}

Cancer becomes health problem worldwide, since the accelerating morbidity and mortality caused by disease progression. According to World Health Organization (WHO), each year 6.25 millions of people are afflicted with cancer. It is predicted that 9 millions of people would die of cancer for the following 10 years (Malcolm, et al., 2008). Cancer growth denoted carcinogenesis, begin with the development of one cell into small colony resided in the same tissue. This small colony undergoes genetic changes which leads to abnormality then malignancy (Bernard, 2000).
Angiogenesis is a physiological process that involves the formation of new blood vessels. Angiogenesis acts by supplying nutrition and oxygen for the cancer cells, carries metabolic waste and biological end product of cancer cells. Therefore the spread of cancer cells to the surrounding cells and tissues is accelerated. The occurrence of angiogenesis shows a change in cancer cell status, from dormant to malignant. Cancer cells induce the angiogenesis through the secretion of various growth factors such as vascular endothelial growth factor (VEGF) and basic fibroblast growth factor (bFGF) (Baker, 2007).

\footnotetext{
*Corresponding author email: kelana_dawley@yahoo.com
} 
Basically, cancer treatment using chemotherapy or herbal medicines are not much different. Both treatments are effective to kill intracellular and extracellular cancer, which spread along the blood stream. Hitherto, cancer treatment by directly killing cancer cells is considered to be less effective because carcinogenic subtituents of cells are still able to spread freely to other tissues en route blood vessels. Therefore, cancer treatment by inhibiting angiogenesis is more effective in treating the disease than to kill the cancer cells directly. Via angiogenesis inhibition, the supply of nutrients and oxygen to cancer cells will be hampered thoroughly, thus resulted in growth inhibition of cancer (Rafii, 2002). Current trend presented societal preference toward natural ingredients. One of the natural ingredient that provides novelty for cancer treatment is pegagan (Centella asiatica). Previous studies of Centella asiatica with asiatic acid as the active compound recommended the application of this plant in the prevention and treatment of cancer (Ruan, 2006; Zheng, 2007). Angiogenesis is contributed to cancer carcinogenesis in the early development of disease. Then, this is the aim of this research to evaluate the role of Centella asicatica to influence angiongenesis.

\section{MATERIALS AND METHOD}

\section{Sample Preparation}

Fresh leaves of Centella asiatica were washed thoroughly with flow water, drained, and dried by exposing indirectly to the sun heat (covered with dark cloth). The sun-dried leaves were then blended and shieved into fine powder. As many as $5 \mathrm{~g}$ of powders was put into a glass beaker, then added distilled water with a temperature of $28^{\circ} \mathrm{C}$ to reach a volume of $200 \mathrm{~mL}$. This process was carried out in an incubator for 24 hours. After that, the mixture was filtered with Whatmann paper no. 4 in order to get the water extract. The extract was then dried with a freeze dryer and stored in a refrigerator with a temperature of $10^{\circ} \mathrm{C}$.

\section{Chemical}

Water extract of Centella asiatica was dissolved in aquadest for test purpose. Angiogenic inductor used in this research was human recombinant bFGF $10 \mathrm{ng} / \mu \mathrm{L}$. Nine days old of embryonated chicken eggs (ECE) specific pathogenic free were used in incubated condition. The $0.01 \mathrm{M}$ Tris- $\mathrm{HCl} \mathrm{pH} 7.5$ was used as bFGF solvent. $10 \%$ phosphate buffered formalin used to preserve CAM membranes.

\section{Anti-angiogenic Assay}

Anti-angiogenic assay was performed on 9 days old ECE chorioallantoic membrane (CAM). A hole was drilled gently on the surface of ECE shell to form a rectangular area with $1 \mathrm{~cm}^{2}$ in width. Through this hole the test solution was implanted using media paper disc (Ribbati, et al., 2007). ECE were divided into 7 groups, each treatment was consisted of five ECE. Treatment I: positive control, $60 \mathrm{ng}$ bFGF administration. Treatment II: negative control, solvent (Tris- $\mathrm{HCl}$ and aquadest) administration. Treatment III: $60 \mathrm{ng}$ bFGF and $75 \mu \mathrm{g}$ water extract of Centella asiatica in aquadest. Treatment IV: $60 \mathrm{ng}$ bFGF and $90 \mu \mathrm{g}$ water extract of Centella asiatica in aquadest. Treatment V: $60 \mathrm{ng}$ bFGF and $110 \mu \mathrm{g}$ water extract of Centella asiatica in aquadest. Treatment VI: positive control group of synthetic antiangiogenesis drug $20 \mu \mathrm{g}$ Celecoxib and $60 \mathrm{ng}$ bFGF administrations. Treatment VII: negative group, $110 \mu \mathrm{g}$ water extract of Centella asiatica in aquadest. After administrated with each treatment, ECEs were incubated in $38-39^{\circ} \mathrm{C}$ with $60 \%$ relative humidity for 72 hours. The ECE were then opened, removed egg contents gently to keep CAMs remain intacted to the eggshell. New blood vessels around the paper discs were counted. To observe the number of VEGF expression, immunohistochemistry was performed. The CAMs around paper discs were collected in $10 \%$ buffered formalin for $\mathrm{HE}$ staining.

\section{Data Analysis}

The number of microscopic and macroscopic new blood vessels formed during observation were analyze using parametric analysis of variance F-test. To compare the differences of means among each treatment group, Duncan multiple comparison test with 95\% confidence interval was employed. Using statistical software SPSS $^{\mathrm{TM}}$ version 16.0 descriptive analysis of VEGF expression was conducted by comparing the results of imunohistochemical staining techniques from each treatment group. 


\section{RESULTS AND DISCUSSION}

The results of macroscopic observation and comparison between bFGF control group untreated with extract and group treated with extract were shown in Fig.1. Observations were followed by counting the number of new blood vessels or capillaries that extend and branch out from great vascular origin. The results of the calculation were presented as means of four replications from each treatment group. The means values of the number of new blood vessels can be seen in Table I. There was no significant difference in the number of blood vessels reduction for each concentration. The difference of means for each treatment was analyzed using Duncan multiple range test. The lowest means value of the number of blood vessels was $110 \mu \mathrm{g}$ of Centella asiatica water extract $+60 \mathrm{ng}$ bFGF treatment group, with the value of $2.60^{\mathrm{c}} \pm 1.14$. These results were not different significantly $(p>0.05)$ with Tris solvents and DMSO control group, with the value of $3.20 \pm 0.83$. It indicates that $110 \mu \mathrm{g}$ of Centella asiatica water extract has equal activity with solvent control group to inhibit the development of new blood vessels induced by $60 \mathrm{ng}$ bFGF. The $75 \mu \mathrm{g}$ and $90 \mu \mathrm{g}$ of Centella asiatica water extract treatment group were not different significantly. Nevertheless, the treatment groups showed inhibition activity toward new blood vessels development $\left(4.00^{\mathrm{bc}}\right.$ $\left.\pm 0.70 ; 4.40^{\mathrm{b}} \pm 1.51 ; 2.60^{\mathrm{c}} \pm 1.14\right)$ compared to $60 \mathrm{ng}$ bFGF control group $\left(7.00^{\mathrm{a}} \pm 1.22\right)$. The $20 \mu \mathrm{g}$ celecoxib positive control group gave means value as much as $2.80^{\mathrm{c}} \pm 0.84$, it was not different significantly compared to $110 \mu \mathrm{g}$ of Centella asiatica water extract treatment group.

The administration of Centella asiatica water extract for each group showed dose dependent manner. These results indicate that the higher concentration of Centella asiatica water extract will resulted in lower development of new blood vessels. The percentage of new blood vessels reduction for each treatment group is listed in Table 2 .
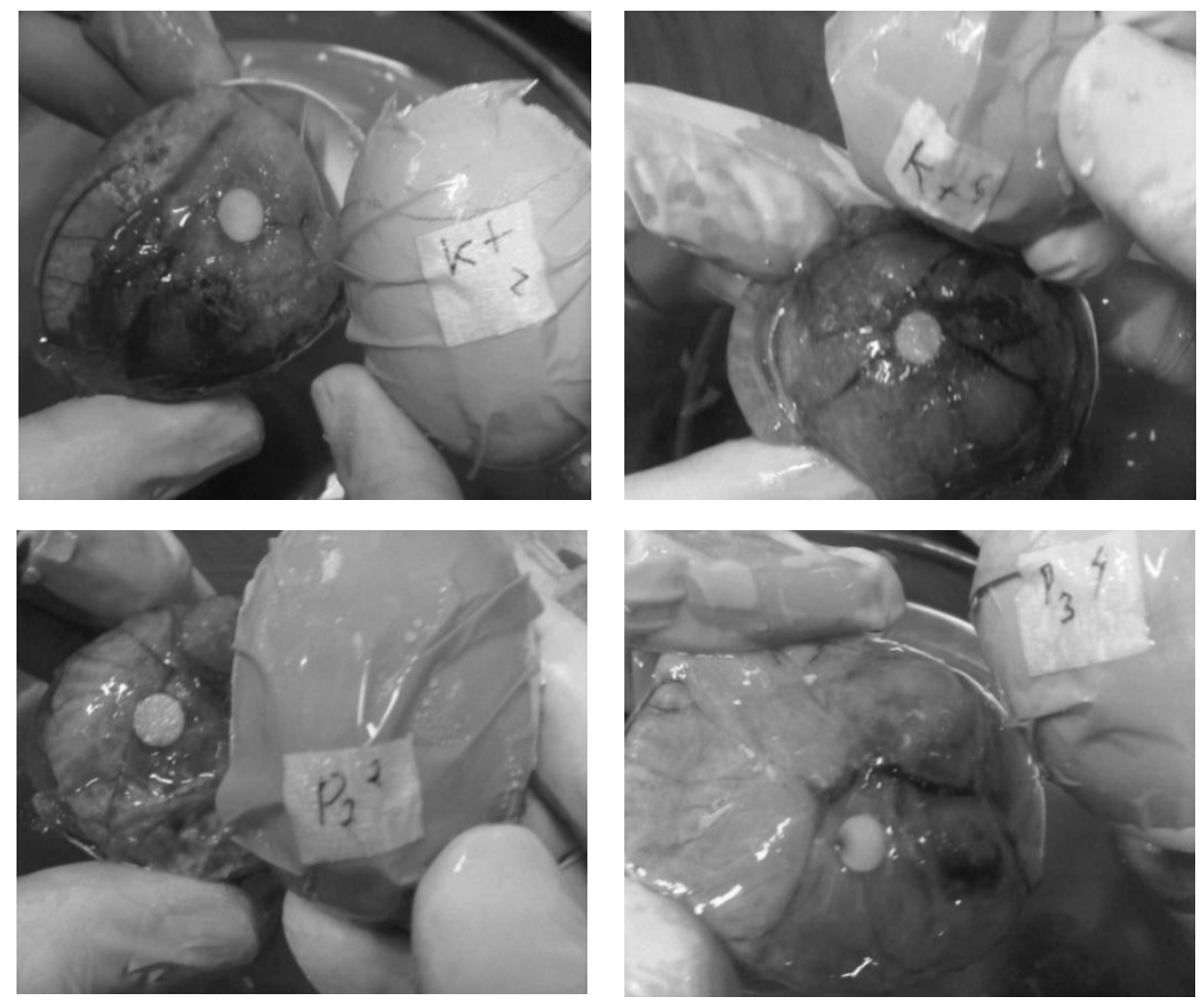

Figure I. The development of blood vessels around paper disc that was placed directly on the CAM. Two images above are bFGF control group untreated with extract. Lower left and lower right images are the group treated with $90 \mu \mathrm{g}$ of extract and $110 \mu \mathrm{g}$ of extract, respectively. 
Table I. The means values of the number of new blood vessels on CAM from each treatment group based on macroscopic observation

\begin{tabular}{l|c}
\hline \multicolumn{1}{c|}{ Treatment groups } & $\begin{array}{c}\text { The number of new blood vessels } \\
\text { (Means } \pm \text { SD) }\end{array}$ \\
\hline $60 \mathrm{ng}$ bFGF control & $7.00^{\mathrm{a}} \pm 1.22$ \\
Tris and DMSO solvent control & $3.20^{\mathrm{bc}} \pm 0.83$ \\
Treatment II : $75 \mu \mathrm{g}$ of Centella asiatica extract $+60 \mathrm{ng} \mathrm{bFGF}$ & $4.40^{\mathrm{b}} \pm 1.5 \mathrm{I}$ \\
Treatment III : $90 \mu \mathrm{g}$ of Centella asiatica extract $+60 \mathrm{ng}$ & $4.00^{\mathrm{bc}} \pm 0.70$ \\
bFGF & $2.60^{\mathrm{c}} \pm 1.14$ \\
Treatment IV : II0 $\mu \mathrm{g}$ of Centella asiatica extract $+60 \mathrm{ng}$ & \\
bFGF & $2.80^{\mathrm{c}} \pm 0.84$ \\
Positive control : $60 \mathrm{ng}$ bFGF $+20 \mu \mathrm{g}$ Celecoxib & $3.40^{\mathrm{bc}} \pm 0.54$ \\
Negative control : II0 $\mathrm{gg}$ Centella asiatica extract & \\
\hline
\end{tabular}

Table 2 . The percentage of new blood vessels reduction in CAM compared to the bFGF control group

\begin{tabular}{|c|c|}
\hline Treatment groups & $\begin{array}{c}\text { Percentage of blood vessels } \\
\text { reduction } \\
(\%)\end{array}$ \\
\hline 60 ng bFGF control & --- \\
\hline Tris and DMSO solvent control & 54.28 \\
\hline Treatment II : $75 \mu \mathrm{g}$ of Centella asiatica extract $+60 \mathrm{ng}$ bFGF & 37.14 \\
\hline Treatment III : $90 \mu \mathrm{g}$ of Centella asiatica extract $+60 \mathrm{ng}$ bFGF & 42.85 \\
\hline Treatment IV : I I $0 \mu \mathrm{g}$ of Centella asiatica extract $+60 \mathrm{ng}$ bFGF & 62.85 \\
\hline Positive control : $60 \mathrm{ng}$ bFGF $+20 \mu \mathrm{g}$ Celecoxib & 60.00 \\
\hline Negative control : I $10 \mu \mathrm{g}$ Centella asiatica extract & 51.30 \\
\hline
\end{tabular}

The highest value in the percentage of new blood vessels reduction was $110 \mu \mathrm{g}$ of Centella asiatica water extract $+60 \mathrm{ng}$ bFGF treatment group, with the value of $62.85 \%$. This was not different significantly $(p>0.05)$ compared to Tris- $\mathrm{HCl}$ and DMSO solvent control group (54.28\%). Whereas $75 \mu \mathrm{g}$ and 90 $\mu \mathrm{g}$ of Centella asiatica water extract treatment group showed percentage of new blood vessels reduction, with the value of $37.14 \%$ and $42.85 \%$, respectively. Both treatments were not different significantly. Almost all treatment groups achieved percentage of new blood vessels reduction in average above $40 \%$, indicating the success of Centella asiatica leaf extracts to inhibit the development of new blood vessels (angiogenesis).

Microscopic observation toward blood vessels formation on CAM is necessary in order to validate macroscopic observation. This observation was carried out by calculating the formation of new blood vessels around the major veins. Conducted on three point of views, the means values were then calculated, results can be seen in Table 3 .

Table 3. The means values of the number of new blood vessels on CAM from each treatment group based on microscopic observation

\begin{tabular}{|c|c|}
\hline Treatment groups & $\begin{array}{c}\text { The number of new blood vessels } \\
\text { (Means } \pm \text { SD) }\end{array}$ \\
\hline 60 ng bFGF control & $93.77 \mathrm{a} \pm 6.51$ \\
\hline Tris and DMSO solvent control & $36.28 c \pm 2.71$ \\
\hline Treatment II : $75 \mu \mathrm{g}$ of Centella asiatica extract $+60 \mathrm{ng}$ bFGF & $55.72^{b} \pm 5.72$ \\
\hline Treatment III : $90 \mu \mathrm{g}$ of Centella asiatica extract $+60 \mathrm{ng}$ bFGF & $48.62^{b} \pm 8.95$ \\
\hline Treatment IV : I $10 \mu \mathrm{g}$ of Centella asiatica extract $+60 \mathrm{ng}$ bFGF & $51.06^{b} \pm 11.59$ \\
\hline Positive control : 60 ng bFGF $+20 \mu g$ Celecoxib & $39.20 c \pm 2.38$ \\
\hline Negative control : $110 \mu \mathrm{g}$ Centella asiatica extract & $36.60 c \pm 5.03$ \\
\hline
\end{tabular}


Microscopic calculation of new blood vessels formation on CAM showed significant difference on means value for each Centella asiatica extract treatment group (75, 90, and $110 \mu \mathrm{g}$ ), but not highly significant $(p<0.01)$. Compared to solvent control group, there is no significant difference on means value of Centella asiatica extract treatment group ( $p>0.05)$. Nevertheless, the results showed that Centella asiatica water extract successfully inhibit the formation of new blood vessels induced by $60 \mathrm{ng}$ bFGF. Histopathologic image of new blood vessel formation showed cross-sectional capillaries formed amidst CAM. Result can be seen in Fig. 2.

Microscopically, new blood vessels denoted as blood vessels that grow and evolve from main veins. They are characterized by round to oval lumens, vascular walls resemblance to thin membranes, homogenous, unaccompanied by another muscles, and have rarely visible endothelial nuclei and blood cells in its lumen. The formation of new blood vessels presented in Fig. 2 were shown on the tip of the black arrow. Reduction in capillary blood vessels density was observed on each treatment. Newly formed blood vessels begin to decrease progressively by increasing concentration of Centella asiatica water extract.

VEGF expression is present on endothelial cells of new blood vessels, which branch out from main veins. This new blood vessels usually appear around the main veins. VEGF expression in cytoplasm or on the surface of endhotelial cells can be detected using anti-VEGF antibody. The administration of $60 \mathrm{ng}$ bFGF in treatment group resulted in VEGF expressions which were dominated by the presence of brown color. The reduction in brown color which indicate a lower expression of VEGF was shown after the administration of Centella asiatica water extract. This phenomenon was appear in dose dependent manner. The result from microscopic observation of VEGF expression is presented in Fig. 3.

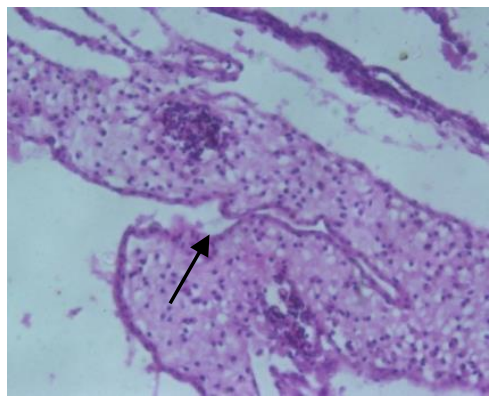

(A)

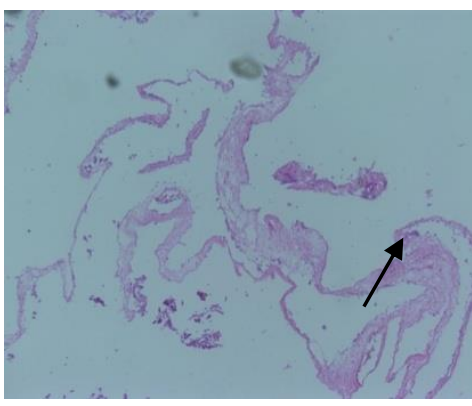

(B)

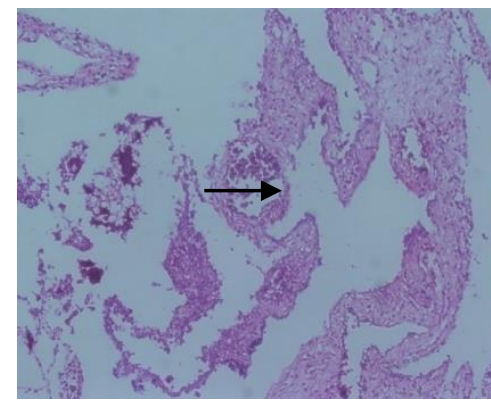

(C)

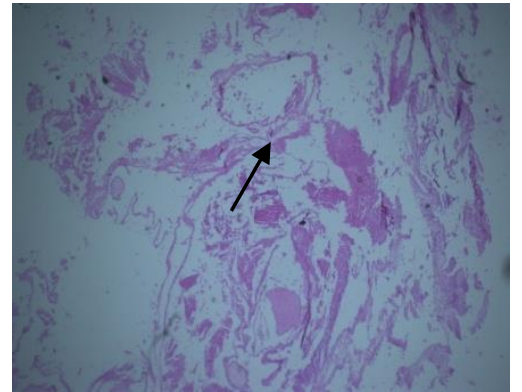

(D)

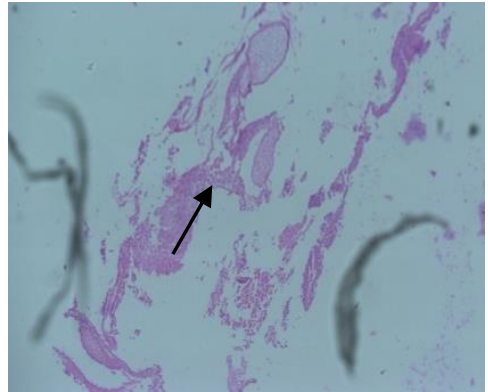

(E)

Figure 2. Cross-sectional capillaries formation on CAM for each treatment group, microscope with 400x magnification. (A) bFGF positive control, (B) solvent control, (C) $75 \mu \mathrm{g}$ extract + bFGF, (D) 90 $\mu g$ extract + bFGF, $(E)$ II0 $\mu g$ extract + bFGF. The arrow $(\longrightarrow)$ showed the formation of new blood vessels. 


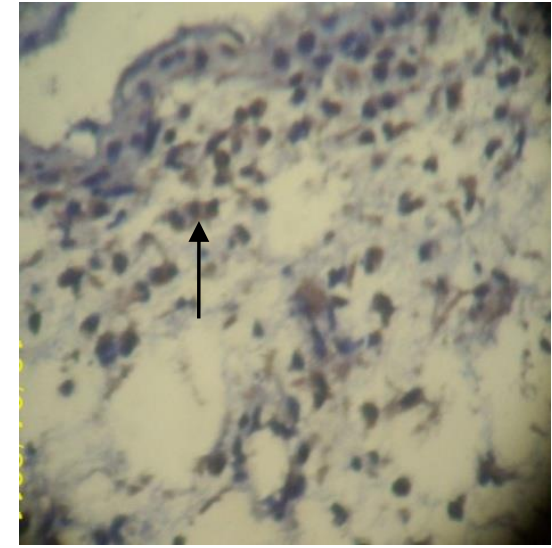

(A)

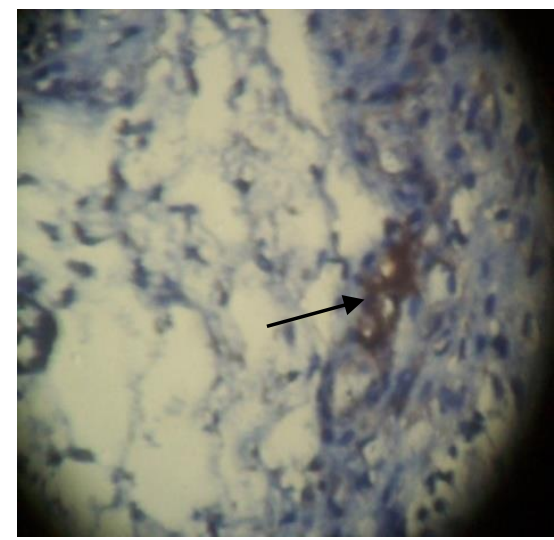

(C)

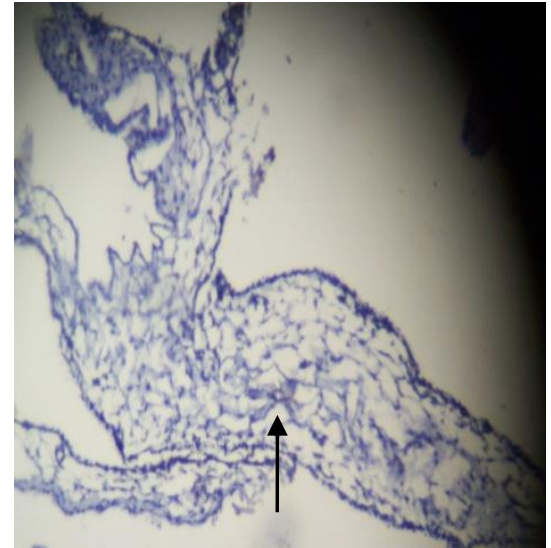

(B)

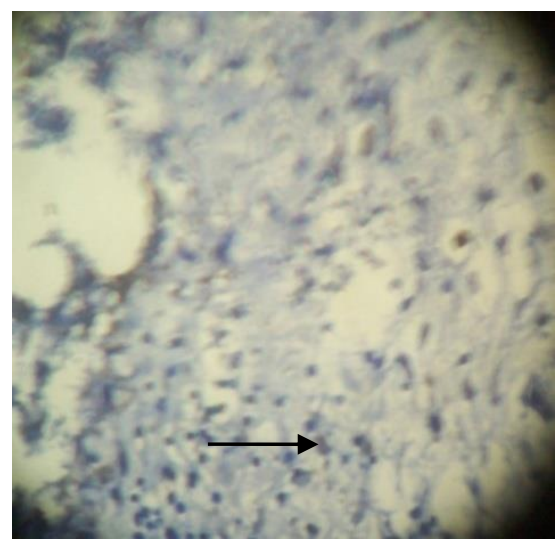

(D)

Figure 3. VEGF expressions in the treatment group are indicated by black arrows. (A) bFGF positive control without Centella asiatica extract, (B) solvent negative control, (C) $75 \mu \mathrm{g}$ of Centella asiatica water extract treatment group, and (D) I I0 $\mu \mathrm{g}$ of Centella asiatica water extract treatment group.

Active compounds in Centella asiatica water extract are responsible in its antiangiogenesis activity. These active compounds comprising triterpenoids, for instances aglycone asiatic acid, madecassoside, and madasiatic acid. The vascular effect of triterpenoids is related to inhibition of collagen production. Collagen has an important role in the wound healing process by improving vascular endothelial (Gohil, et al., 2010). Among these tritepenoids, aglycon asiatic acid is dominant to inhibit the expression of angiogenic factor VEGF. It is in accordance with the research conducted by Kavitha, et al. (2011) that 5-20 $\mu \mathrm{M}$ of asiatic acid inhibits stimulation factor for VEGF expression and formation of capillary tubes. Based on this study, it is concluded that Centella asiatica water extract inhibits the growth of new blood vessels on CAM induced by bFGF as the result of microscopic and macroscopic observations, and can inhibit the expression of VEGF. As many as $110 \mu \mathrm{g}$ of Centella asiatica water extract provide highest barrier for the formation of new blood vessels.

\section{REFERENCES}

Baker, T., 2007, Enzyme Eliminated by Cancer Cells Holds Promise for Cancer Treatment, Website, http://www.eurekalert.org/pub_release s/2007-07/mcog-eeb07/807.php.

Gohil, K.J., Patel, J.A. and Gajjar, A.K., 2010, Pharmacoligical review on Centella asiatica. A Potential Herbal Cure-all, Indian J. Pharm. Sci., 72(5), 546-556.

Kavitha, C.V., Agarwal, C., Agarwal, C.R. and Deep, G., 20II, Asiatic Acid Inhibits Pro-angiogenic Effects of VEGF and Human Gliomas in Endothelial Cell Culture Models, Plos One., 6(8), 22745. 
Moore, M.A., Manan, A.A., Chow, K.Y., Cornain, S.F., Devi, C.R., Triningsih, F.X., et al., 2008, Cancer Epidemiology and Control in Peninsular and Island South-East Asia - Past, Present and Future, Asian Pac. J. Cancer Prev., I I (suppl 2), 8I-98.

Rafii, S., Heissig, B. and Hattori, K., 2002, Efficient Mobilization and Recruitment of Marrow-Derived Endothelial and Hematopoietic Stem Cells by Adenoviral Vectors Expressing Angiogenic Factors, Gene Ther., 9(10), 63I-64I.
Ruan, W.J., Lai, M.D. and Zhou, J.G., 2006, Anticancer Effects of Chinese Herbal Medicine, Science or Myth?, J. Zhejiang Univ. Sci. B., 7, I006-1014.

Weinstein, I.B., 2000, Disorders in Cell Circuitry During Multistage Carcinogenesis: The Role of Homeostasis, Carcinogenesis, 2I(2), 857-864.

Zheng, C.J. and L.P. Qin., 2007, Chemical Component of Centella asiatica and their Bioactivities, Zhong $\mathrm{Xi}$ Yi Jie He Xue Bao., 5(3), 348.35I. 